\title{
EL AÑIL EN LA VENEZUELA ILUSTRADA. UNA HISTORIA INCONCLUSA
}

\author{
POR \\ FÉDÉRIQUE LANGUE \\ CNRS - París
}

Este trabajo intenta ofrecer una síntesis acerca de un ramo poco estudiado de la economía colonial tardía, especialmente en el caso de Venezuela, tanto desde el punto de vista económico (condiciones de la producción, rentabilidad del cultivo, cantidades destinadas a la exportación y mercados) como social (funcionamiento de las haciendas añileras y tipos de propiedades). Se contempla la fulgurante trayectoria de indigoferea tintorea desde su introducción en la Capitanía General por el vasco Antonio de Arbide hasta el ocaso de su incipiente vocación comercial en vísperas de la Independencia.

En el mundo hispánico pasó a la posteridad el añil, o mejor dicho la planta conocida bajo el nombre de indigoferea tintorea, con motivo del tinte azul que se podía extraer de esta planta. Bastante bien conocida y difundida en Nueva España donde los colorantes fueron objeto de activo comercio desde la época prehispánica, el "pastel" o xiquilite continuó su expansión por América Central a lo largo del siglo XVII, y sobre todo, en el siglo XVIII. Guatemala se convirtió entonces en el centro de la industria añilera, mediante la creación de obrajes junto a las haciendas o plantaciones especializadas en el cultivo de este fruto. En el siglo XVIII se le dedicaron varios textos y tratados - así como varios reglamentos, en 1782 y 1784 en el caso de Guatemala - con el fin de fomentar la actividad añilera en su conjunto.

Venezuela no experimentó verdaderamente un auge comercial hasta el último tercio del siglo XVIII. La primera pregunta que surge al respecto se refiere, por lo tanto, a la difusión de la planta: si bien 
se comprobó la existencia de la misma en otras regiones de América, sólo de manera escasa se menciona para Tierra Firme antes de esa fecha. En realidad, convendria matizar esta apreciación en la medida en que, en varios relatos de viajeros, se señala la existencia en el siglo XVII de una variedad local del añil. Parece ser incluso que la producción y la utilización de esta planta se reglamentaron de manera muy precisa como lo atestiguan las Ordenanzas de Mérida (16201621) referentes a las actividades productivas de los encomenderos de la región andina. Otros informes más tardíos que se remontan a la segunda mitad del siglo XVIII indican además que esta planta crecía en forma "silvestre" en la proximidad de los pueblos. Abundaba incluso en la mayoría de las regiones que conformaban la Capitanía General de Venezuela. Ahora bien, no se explotaba con un propósito comercial, a diferencia de lo que estaba sucediendo en el mismo momento en otras regiones de América española. En el mejor de los casos, se utilizaba para teñir los hilos de algodón que servían para la confección de hamacas o chinchorros, y también para los vestidos de los pobres como fué el caso en las localidades de San Cristóbal y de Lobatera, siempre en la comarca merideña ${ }^{1}$.

\section{ORÍGINES Y ACTORES DE LA PRODUCCIÓN AÑILERA EN VENEZUELA}

No fue hasta la década de 1770 cuando se contempló el cultivo comercial del añil y se introdujo oficialmente en la economía colonial de Venezuela, para abastecer a unas manufacturas y obrajes y,

\footnotetext{
SigLAS UTILIZADAS:

ACM: Archivo del Consejo Municipal, Caracas.

AGI: Archivo General de Indias, Sevilla.

AGN: Archivo General de la Nación, Caracas.

1 Para una aproximación a la historia de los colorantes en el área mesoamericana, véase Jean-Pierre BERTHE, "El cultivo del pastel en Nueva España", Historia Mexicana, vol. IX nº 3, 1960, pp. 1-28 y más recientemente, María Justina SARABIA VIEjo, "Evolución de los colorantes mesoamericanos en el siglo XVIII", en Europa e Iberoamérica. Cinco siglos de intercambios, Sevilla, AHILA/Junta de Anadalucía, 1992, vol. I, pp. 321-342; de la misma autora, La grana y el añil. Técnicas tintóreas en México y América Central, Sevilla, EEHA, 1994; sobre los destinos del añil en México, véase Gerardo SANCHEZ DiAZ, "Cultivo, producción y mercado del añil en Michoacán en el siglo XIX", Nuestra Historia, Caracas, $\mathrm{n}^{\circ}$ 1991,pp. 35-44; Diccionario de Historia de Venezuela, varios autores, Caracas, Fundación Polar, 1988, vol. 1, p. 147. Eduardo ARCILA FARIAS, Economía colonial de Venezuela, Caracas, Italgráfica, 1973, 2a ed., tomo I, p. 234.
}

R. I., 1998, n. $^{\circ} 214$ 
sobre todo, para la exportación. Se estima que para 1772, el cultivo competía con el del cacao en los valles de Aragua, ubicados cerca de la ciudad de Caracas. A los dos años se registraron las primeras exportaciones desde La Guaira. En 1774, y quizás haya que buscar allí el origen de la confusión que consiste en ubicar en ese momento la introducción del añil en Venezuela, explícitamente evocada, y en estos términos, en las actas del Consulado de Comercio. Después del fallido intento de José de Aponte de introducirlo en Venezuela, el guipuzcoano Antonio de Arbide importó desde Guatemala una variedad nueva indigofora añil. Junto al sacerdote y coterráneo suyo Pablo de Orendaín, empieza a sembrar en la región de Maracay. Fue verdaderamente a partir de esa fecha cuando se empezó a desarrollar el referido cultivo en la provincia, beneficiándose de las medidas "proteccionistas" que mandó adoptar el Gobernador de entonces, José Carlos de Agüero e impulsado por los emigrantes españoles, sobre todo por los vascos. Parece ser que al añil silvestre se le sustituyó por esta nueva especie, que no tardó en prosperar. De igual manera se intentó aclimatarla en otras regiones, así en las riberas del lago de Valencia, intento coordinado por Alonso Tomás Escobar en una propiedad de Tomás de Sandoval. A pesar del éxito conseguido por los asociados, fue en la propiedad "Agua de obispos", ubicada en Nirgua (Yaracuy), y perteneciente al maestro de campo Blas Ambrosio Jiménez, donde encontraron las condiciones pedológicas más propicias (naturaleza del suelo, proximidad de unos ríos para accionar el molino que movía el líquido en el cual se preparaba el tinte ${ }^{2}$.

No carece de interés considerar el papel que desempeñó el empresario Antonio de Arbide en la comercializacion de este cultivo. Se considera a Arbide como el introductor junto a su asociado Pablo de Orendaín, del cultivo comercial del añil en Venezuela. Instalado en Nueva España y más precisamente en Veracruz, Arbide habría llegado a Venezuela traído por la Compañía Guipuzcoana hacia 1768 , para que fomentara el cultivo del añil en mayor escala. A petición de Manuel de Clemente y Francia, envió a su hermano Manuel a Guatemala para que éste trajese la semilla de indigofera añil tinc-

2 ARCILA FARIAS [1]. Sobre el intento de Aponte en 1767 y para una breve reseña de estos primeros años, véase Adela SANCHEZ NARIO, "La introducción del añil como planta comercializable en Venezuela", Venezuela en el siglo de las Luces (María Carmen MENA GARCIA, coord.), Sevilla-Bogotá, Muñoz Moya Editores, 1995, pp. 76-77. 
toria. De suerte que en su Viaje a la parte oriental de Tierra Firme publicado en París en 1806, Francois Depons señala que fue en 1774 cuando el sacerdote don Pablo de Orendaín y don Antonio de Arbide empezaron a dedicarse al cultivo del añil, provocando la sorpresa de sus vecinos quienes habían intentado en vano incentivar el cultivo (pero de la variedad silvestre) en gran escala para teñir tejidos, mantas y hamacas de algodón ${ }^{3}$.

Arbide se estableció por su cuenta, compró tierras, arrendando otras, y se convirtió en el primer productor de los valles de Aragua en la década de los setenta. En 1784, cuando Francisco de Saavedra decidió reglamentar la comercialización de este producto y de mejorar la calidad de los productos destinados a la exportación, se nombró a Arbide veedor para la región de Maracay. Era también comerciante y vendía mercancías importadas en esa ciudad. Un último dato acerca del personaje: con motivo de haber introducido en Venezuela la siembra del añil, solicitó el "permiso para introducir géneros extranjeros de lícito comercio hasta en cantidad de 100.000 pesos y extraer su importe en frutos para las colonias amigas", solicitud que le fue denegada por la Corona. Se benefició, sin embargo, del apoyo del Gobernador Capitán General, quien propuso que se le concediera una pensión de Real Hacienda: de tal forma que se le asignó 500 pesos anuales (y en caso de fallecer el interesado, a su viuda) por Real Orden de 2 de octubre de 1805, sobre el Fondo de Avería del Consulado de Comercio 4 .

\section{LA EDAD DE ORO DEL CULTIVO Y DE SU COMERCIALIZACIÓN}

La considerable extensión de las zonas de cultivo, desde Aragua hasta el suroeste (Barinas) y la apertura de los mercados llevaron a los cosecheros y a las autoridades locales a solicitar medidas encaminadas a proteger esta producción e incentivar de esta manera la exportación de la misma hacia Europa donde se iba ampliando el

\footnotetext{
3 Francisco Depons, Viaje a la parte Oriental de Tierra Firme en la América meridional, Caracas, Banco Central de Venezuela, 1960, tomo II, pp. 25-26.

4 Depons [3], p. 167. Diccionario de Historia de Venezuela [I], p. 167. AGN, Actas del Consulado, 2529: junta ordinaria de 26 de septiembre de 1804 (oficio de 12 de septiembre del Capitan General).Eduardo ARCILA FARIAS, Documentos del Real Consulado de Caracas, Caracas, UCV, 1964, doc. 109, pp. 109-110: sesión de 11 de abril de 1807.
}

R. I., 1998, n. $^{\circ} 214$ 
mercado de los colorantes. Las alzas de precios y las exenciones de impuestos fueron las principales medidas que reivindicaron ambas partes. Entre estas solicitudes figura la del factor José de Amenabar, presentada al gobernador José Carlos de Agüero en enero de 1774. En este documento, Amenabar resaltaba la posibilidad de conseguir ingresos nuevos, especialmente en Europa, por medio de la producción y de la comercialización del añil. calificada de "industria ventajosísima de esta provincia". En febrero del mismo año, el gobernador informó personalmente a la Corona, lo mismo el año siguiente. Hasta les adjuntó a sus "representaciones" unas muestras de esta planta para que se pudiera comprobar la calidad de ésta; pidió en especial que la Corona edictara reglas para el buen funcionamiento de este nuevo ramo de la economía. En una carta fechada del 16 de octubre de 1776, insiste en la progresión que va experimentando el cultivo del añil en los valles de Aragua pero asimismo señala que va cundiendo el descontento con motivo de la negativa de los dirigentes de la Compañía Guipuzcoana de subirle el precio y de comprar la cosecha en el momento oportuno. De ahí la falta de interés que se registró entre los productores por cuestionar de esta manera la vocación comercial de este producto.

La creación de la Intendencia en 1976, de la que se podía pensar que contribuiría en incentivar la agricultura local, no trajo de inmediato las ventajas esperadas. En cambio, sí tuvo como consecuencia más inmediata la regulación y luego la interdicción del comercio del añil con las colonias extranjeras. En el mismo momento, José de Abalos le advirtió a la Corona, en una carta del 4 de abril de 1777, que no se le concedía al añil la importancia que se merecía. Por Real Orden del 26 de abril de este año, se le confirma al gobernador Luis Unzaga y Amézaga que el añil venezolano es de una calidad comparable a la variedad más famosa de Guatemala, aseveración defendida desde 1774 por el cabildo caraqueño. En el mismo documento, la Corona reitera su apoyo a los cosecheros y puntualiza que se les ha dado orden a los factores de la Guipuzcoana para que compraran a precio fijo las cantidades de añil que les fueran llevadas por los labradores y cosecheros. Asimismo se dispuso, por Real Orden del 13 de abril de 1777, y con el fin de promover el cultivo y la comercialización de la planta, que se reducirían a la mitad los derechos de extracción del fruto de Venezuela y se autorizó su venta en paises extranjeros. Cada año se fijaría el precio de acuerdo a las indicaciones 
de los productores y de los comerciantes, bajo el control de veedores quienes certificarían la calidad de los productos. La junta reunida al efecto dictaminó que había cuatro clases de añil. Otra Real Orden, del 28 de junio, le recomendó al gobernador lo siguiente ${ }^{5}$ :

“...Que procure adelante en esta Provincia cuando sea posible su siembra y beneficio, haciendo entender a los que se dedican a su cultivo, las utilidades que promete a sus cosecheros por el alto precio en que se vende el buen añil en estos Reinos, y la salida que S.M. permitirá del sobrante a los paises extranjeros".

En el mismo documento se solicitó más informaciones relativas al costo inicial, a los gastos ocasionados por este cultivo y el momento de los derechos cobrados con motivo de su remisión a España.

En 1978, fecha simbólica para el comercio americano en su conjunto (sin embargo el decreto relativo al comercio libre no se hará extensible a Venezuela sino hasta 1789), la Compañía Guipuzcoana decide, habida cuenta del éxito de la producción de añil, autorizar la venta del mismo, suprimiendo la mediación de la junta para la fijación de los precios y a pesar del decreto real expedido el año anterior en este sentido. Se confirmó esta disposición por otra Real Orden de 20 de octubre de 1778: en adelante se efectuará la regulación de los precios del añil partiendo de la oferta existente y de la demanda al respecto. Más todavía: para fomentar la producción, y con tal de que sea de una calidad mínima, en adelante se declaró el fruto de toda contribución a la salida de Venezuela y a la entrada en España. En 1786, el añil todavía no pagaba derechos de exportación.

En 1870 sin embargo, El Intendente Abalos se preocupó por el nivel alcanzado por los precios en la Provincia, hasta tal punto que autorizó la exportación del añil via la isla de Curazao, lo que conllevaba la posibilidad de intercambiarlo con mercancías holandesas, tanto en el marco del comercio local como por lo que se refiere a los intercambios con la Península, hechos más difíciles por la coyuntura diplomática. Pero las relaciones con Curazao no se limitaron al simple tránsito del añil ya que el mismo Abalos autorizó el trueque de cacao, añil, tabaco y mulas por harina y mercaderías holandesas ${ }^{6}$. El

\footnotetext{
5 Arcila Farias [1], tomo I, p. 337. Diccionario de Historia de Venezuela [1]

6 ARCILA FARIAS [1], tomo I, p. 352.
} 
intendente Saavedra estimaba por su parte que el precio de la libra de añil flor había caído de 13 a 7 reales cuando el costo de producción era de 10 reales y que se vendía en 21 reales en la Península.

El fomento del cultivo del añil en el núcleo comercial de Maracay, en Turnero y en La Victoria contribuyó en transformar estas localidades, a la par que provocaron conflictos con los productores de caña de azucar y los ganaderos. El mismo Antonio de Arbide tuvo que soportar las consecuencias de estas rivalidades en 1780 , cuando se le exigieron unos 50.000 pesos con motivo de los perjuicios que conllevaría para la salud pública, la ganadería y los otros cultivos el hecho de botar las aguas usadas por el beneficio del añil en las acequias. Si bien sus contrarios no consiguieron ganar este juicio, se multiplicaron en adelante las reivindicaciones en este sentido. Fueron hacendados como Andres Fuenmayor, Pedro Francisco Jiménez, Miguel Alvarez y Manuel Macero, quienes encabezaron la protesta. En sentido inverso, los productores de añil lamentaban la falta de mano de obra cuando otros cultivos la necesitaban o también cuando se requisaba para obras públicas en la Guaira o para el batallón de Veteranos locales. Los hacendados denunciaron a la unanimidad esta contratación forzada, invocando la decadencia de sus haciendas de añil y pidiendo la intervención de la Corona. En 1788, los cabildantes necesitan del Intendente que se reciba frutos (cacao y añil) en pago de negros a los precios establecidos (entonces 12 reales por una libra de flor de añil, el sobresaliente a 1 y el corte a 8$)^{7}$.

La verdad es que, al igual que otro de los cultivos más importantes de la provincia, el tabaco, el añil empleaba sobre todo, aunque no exclusivamente, mano de obra libre. Si consideramos las evaluaciones de Humboldt, de 1789 a 1795 , se necesitaba de unos 4.000 a 5.000 jornaleros en los valles de Aragua para trabajar durante dos meses en la recolección y en la preparación del añil.Cuando se dió la crisis de sobreproducción de 1787 y que el Intendente Francisco de Saavedra decidió indagar las razones de semejante situación, los productores de añil de la región de Maracay confirmaron que la mayoría de las haciendas especializadas en este fruto, si no todas, recurrían a jornaleros a quienes se pagaba seis o siete pesos al mes

7 ACM, Actas del Cabildo, 1788: sesión del 28 de julio de 1788. 
(además de la comida). Aproximadamente como 20.000 jornaleros se empleaban ya en este ramo de la economía 8 .

Pese a esas dificultades circunstanciales, el añil se conviertió en el segundo producto de exportación a fines del periodo colonial. De ahí, los intentos por controlar instituciones locales tan decisivas en este aspecto como los tenientazgos de justicia que implicaban poderes en lo administrativo, en lo judicial y en lo militar. A partir de la década de los ochenta, el hacendado Antonio Fernández de León empezó a influir sobremanera en los nombramientos de los alrededores de Maracay, de suerte que, en vísperas de la independencia, eran allegados suyos los que ocupaban estos cargos ${ }^{9}$.

Entre los cargos que requerían realmente la vigilancia de los interesados estaban los de veedores. En 1794, el Consulado de Comercio contemplaba la necesidad de nombrar veedores de añiles que fuesen capaces y de fiar:

\footnotetext{
“...que fuesen personas blancas y honradas, de probidad y conocimiento el más perfecto de las calidades del fruto, para evitar el grave perjuicio que padece el comercio en la poca inteligencia o falta de legalidad con que se han reconocido hasta ahora por los negros y mulatos que practicaban esta operación de que ha resultado el detrimento que dicho fruto ha experimentado...".
}

Salieron electos en estas condiciones personajes tan respetables como Francisco Baez, Francisco Arámburu, Martín Belaunzarán, Antonio Arriezurrieta, Josef Vicente Galguera y Félix Martínez. Asimismo se decidió que el veedor recibiría, la mitad del comprador y la midad del vendedor, cuatro reales por cada zurrón sencillo o de unas 100 libras que reconociera, y 8 reales por el doble o por una cantidad superior a 8 arrobas $^{10}$.

\footnotetext{
8 ACM [7], p. 148; Alejandro de HuMBOLDT, Viaje a las regiones equinocciales del Nuevo Continente, Caracas, Ed. del Ministerio de Educación, 1956, tomo II, pp. 70-71; AGI, Caracas, 501: memorial de los cultivadores de añil, 26 de mayo y 2 de julio de 1787; Informe de Saavedra, 23 de noviembre 1787.

9 Michael McKinley, Caracas antes de la Independencia, Caracas, Mote Avila, 1987 (Cambridge Univerity Press, 1985), p.175.

10 AGN, Actas del Consulado, 2526: Junta Ordinaria del 26 de agosto de 1794.
}

R. I., $1998, \mathrm{n}^{\circ} 214$ 


\section{LOS PAISAJES DEL AÑIL: LAS ZONAS DE PRODUCCIÓN}

A partir de 1784, se dintinguen varias zonas especializadas en el cultivo del añil: San Carlos, Tinajos, San Francisco Javier de Agua de Culebra (para la variedad silvestre); Sabana de Ocumare, Cúa y Guanare, recién creadas; Cojedes, Sarare, El Pao y Guacara; en cuanto a las haciendas de la Victoria (valle de Aragua), arrojaban una producción de 150 arrobas al año y en los años 1720, Pedro José de Olavarriaga recuerda las facilidades que había para la siembra de añil aunque fuera silvestre: asimismo se registraron cultivos de añil en los valles de Tuy, Cagua y Turmero, pero eran las tierras cercanas a Maracay que seguían siendo las más productivas, con una producción anual estimada en 4.000 arrobas para las sesenta haciendas instaladas en las inmediaciones de la ciudad. Sin embargo, de las 220 haciendas registradas en 1785-1787, más de la mitad estaban ubicadas en la jurisdicción de La Victoria, o sea. en el valle de Aragua, siendo el otro lugar de concentración el valle del Tuy precisamente.

Se estima en un estudio reciente, que el tamaño físico de las grandes haciendas añileras de Aragua osciló entre las 188 y 600 Has., superficie inferior a la de las haciendas cacaoteras $(6.595,2$ Has. Estas propiedades comprendían oficinas - aunque rudimentarias y de poco valor-, máquinas de agua para el beneficio del añil (que se realizaba mediante un proceso de maceración), tanques, piletas, paletas de batir añil y ruedas. Está comprobado que estos valles, las grandes haciendas añileras recurrían mano de obra esclava, lo que no constituía, sin embargo, una garantía de productividad. En 1793, se registra la presencia de 320 esclavos en 15 de estas haciendas, o sea un promedio de 21 esclavos por explotación. En la jurisdicción de Maracay, la hacienda de añil — junto a una arboleda de cacao- del isleño Andrés Díaz totalizaba 39 esclavos; en la de Juan de Castellanos, que también era de caña de azúcar, eran 47 los esclavos identificados, pero eran solamente 18, o sea apenas el $40 \%$ del total, los que se dedicaban efectivamente a laborear en la hacienda (un porcentage elevado se encontraba inhabilitado por su edad o por problemas de salud). Hay que subrayar - siempre en esta región - que las haciendas que combinaban mano de obra esclava y jornaleros tenían superficies inferiores, entre 24 y 160 Has. aproximadamente. Eran predominantemente de "empresarios" vascos, canarios, catalanes y de otros españoles "europeos", y su 
funcionamiento no difería mucho del de las grandes propiedades esclavistas ${ }^{11}$.

La expansión del comercio del añil tuvo como consecuencia la asociación de los pequeños productores, especialmente de los cosecheros, en las llamadas "compañías a medias" o por medio de arrendamientos, que permitían fundar con más facilidad haciendas de añil, café y otros cultivos locales en tierras hasta entonces desocupadas y a veces propiedad de ellos. Otros solicitaron préstamos en numerario y efectos diversos ante los comerciantes o bodegueros, ofreciendo la cosecha y sus bienes como garantía. Tal fue el caso de la tercera categoría de explotación añilera que se ha logrado identificar para el valle de Aragua. Estas haciendas de mediano tamaño (con un promedio de 60 Has.) se asemejaron de hecho a empresas comerciales, con relaciones contables y un capital a veces importante. Las dirigían con frecuencia grandes comerciantes como Felipe de Llaguno, Juan Joseph de Mintegui y Pablo Orendaín, asociados precisamente en una de estas empresas. Pablo Orendaín había fundado con Juan Joseph de Mintegui (comprador de dos de las mencionadas propiedades $\mathrm{y}$, por lo visto, agente financiero del conjunto) hasta tres haciendas de este fruto y en estas condiciones. Los jornaleros procedían de los llanos de Guárico, Cojedes y del mismo valle de Aragua, con sueldos estimados entre 1 y 3 reales, en numerario, $o$ parte de géneros y especies, y en todo caso inferiores a las remuneraciones de los mayordomos (hasta 286 pesos anuales). Ahora bien, la escasez de peones libres, y la naturaleza del trabajo (considerado poco saludable) obligó a muchos de estos empresarios a pagar a los jornaleros hasta en momentos en que no se necesitaban, o por anticipado, para disponer de mano de obra en el momento preciso. De ahí las rivalidades que se entablaron en el valle de Aragua entre varios de estos hacendados para retener esta mano de obra flotante, a veces en perjuicio de la rentabilidad inmediata de la empresa ${ }^{12}$.

El cultivo del añil se extendió en estas condiciones a la totalidad de la Intendencia: hasta Maracaibo, la isla de Margarita (San Juan

11 Pedro José de Olavarriaga, Instrucción general y particular del estado presente de la Provincia de Venezuela en los años de 1720 y 1721, Caracas, Fundación Cadafe, 1981, pp. 59-60; Germán PACHECO TROCONIS, "Las haciendas de añil en los valles de Aragua en las últimas décadas del período colonial (1767-1830)", en Estudios de Historia Social y Ecónomica de América, no 11, 1994, pp. 349-364.

12 PACHeCo Troconis [11], pp.362-363. 
del Valle), a Barcelona y Cumaná (la preparación del añil se llevaba a cabo en Cumanacoa, San Fernando y Arenas cuyas añilerías se hicieron famosas a fines del siglo XVIII; sus productos, que se podían equiparar con los de Guatemala, se hicieron más famosos que los de Caracas, por estar aquéllos adulterados con frecuencia con el fin de aumentarles el peso), o también en las inmediaciones de Angostura (en los años 1787-1788). En la provincia de Barinas, tan solo 17 haciendad (Barinas, Barinitas, Nutrias, Obispos...) arrojaban una producción de 588 arrobas.

El caso de Barinas resulta particularmente ilustrativo de la política directiva, por no decir intervencionista, y en todo caso voluntarista, adelantada por las autoridades locales en el campo de la economía regional y especialmente por lo que toca a este producto. Según las evaluaciones hechas por el gobernador Fernando Miyares, a fines de 1787 el cultivo del añil, pero tambien del algodón, del café, del cacao, de la caña de azúcar y hasta del achote (onoto) se hallaba "muy a los principios" a pesar de las ventajas existentes, entre ellas, la fertilidad del suelo y las facilidades que brindaban para su extracción los ríos de Apure y Orinoco. Cuando Miyares se propuso transformar el panorama económico barinés, tomó varias medidas con el fin de fomentar la agricultura y de estimular el comercio, poniendo especial empeño en el cultivo del añil.

En 1783, se estimaba ya en 40.000 pesos la producción total de esta zona pero la falta de mano de obra incitaba a los dueños de haciendas de añil a que abandonaran las siembras. Pocos eran además, y como indicó el Gobernador en una carta del 10 de junio de 1788 dirigida a Antonio Valdés, los frutos extraibles hacia España, a excepción del tabaco de cura seca, y habida cuenta de la falta de numerario. Tal era el estado de ánimo del acaudalado don José Ignacio del Pumar, alférez de la ciudad de Barinas, cuando Miyares asumió el cargo de gobernador de la provincia, tenía entonces tres haciendas de este fruto, de las que consideraba que estaban "perfectamente establecidas" pero que pensaba abandonar. Animado por el gobernador a que siguiera adelante con el cultivo del añil, Pumar señaló que en 1787, muchas siembras se habían emprendido efectivamente a instancias del gobernador: eran entonces 39 las haciendas de añil, y producían 1.356 arrobas al año. El mismo había solicitado 150 esclavos con el fin de solucionar la falta de peones. Ahora bien, la escasez de mano de obra esclava fue resuelta por el gobernador si- 
guiendo otra vía: dispuso que unas cuadrillas de indios trabajaran a jornal en las estancias de los españoles. El 23 de mayo de 1788, el cabildo de Barinas elogió la labor del gobernador, subrayando que

"la providencia de favorecer la agricultura dando aplicación a los indios, ha mejorado mucho la constitución de esta Provincia, cuya prueba no puede estar más visible, pues el añil ha sido suficiente de año y medio a esta parte para cubrir el pago en Caracas y Maracaibo, de las gruesas partidas de géneros de Castilla que han conocido en este tiempo tan corto de que no había ejemplo hasta ahora ${ }^{13}$.

En julio del mismo año, el gobernador Miyares le ratificó a Antonio Valdés el éxito de sus providencias, y puntualizó lo siguiente:

\footnotetext{
"Las cosechas del cacao y añil que son de fácil cultivo van tomando bastante incremento y llegarán a componer tres ramos fuertes de comercio, si se concede la provisión de negros que tengo solicitada a V.E.".
}

De hecho, las cifras hablan por sí solas: en 1789, Barinas extrajo desde San Fernando de Apure hacia la provincia de Guayana - por vía fluvial- 1.863 libras de añil. Asimismo se empezó a sacar este fruto hacia Maracaibo y Caracas, con bastante frecuencia y a cambio de géneros de Castilla, herramientas y caldos. El año anterior, el añil enviado a España había permitido la compra de 100.000 pesos de géneros diversos y se habían intensificado las relaciones comerciales de Barinas con las otras provincias venezolanas, especialmente con la Guayana como lo indicó Alejandro de Humboldt quien no vacila en calificar a la pequeña ciudad de San Fernando de Apure de "almacén de ese comercio de ríos"14.

Entre 1775 y 1783-1785 la producción creció como promedio de 8.710 libras a 163221 fanegas. En 1786-1790, ésta creció hasta 294 023 libras, en 1791-1795 hasta 718.074 y en 1809 hasta 697.451 .

13 Virgilio TosTA, Historia de Barinas, tomo I, 1577-1800, Caracas, Academia Nacional de la Historia, 1986, col. "Fuentes para la Historia Colonial de Venezuela" n 183, pp. 386-388.

14 TosTa [12]; Sobre la conformación del espacio fluvial Guyana-llanos en el siglo XVIII, véase Tarcila BRICEÑO DE BERMUDES, Comercio por los ríos Orinoco y Apure en la segunda mitad del siglo XIX, Caracas, Ed. Tropycos, 1993, cap. 1.

R. I., $1998, \mathrm{n}^{\circ} 214$ 
Los precios de la libra de añil fluctuaron entre 11 y 13 reales de 1783 a 1786 , entre 12 y 14 reales de 1793 a 1796 y cotizaron a un promedio de 12 reales en 1808-1809: en realidad, entre 13 reales en el mercado de Caracas, y 8,5 dependiendo de la calidad de las tres formas de flor, sobre y corte. En este sentido, se puede considerar que la progresión de las exportaciones participó de la diversificación de la economía venezolana que se fue afirmando en las postrimerías del siglo XVIII. Para el mismo periodo, el porcentaje alcanzado por el añil en el valor total de los principales productos de exportación pasó del $1 \%$ en 1775 al $15 \%$ en 1784-1785 (comercio registrado entre el puerto de La Guaira y España exclusivamente; hay que recordar al respecto que el $95 \%$ del comercio de la provincia transitaba por La Guardia), el 40\% en 1791-1795 y el 30\% en $1809^{15}$.

\section{UN INTERVENCIONISMO CIRCUNSTANCIAL}

Las grandes variaciones en los precios del añil justificaron el hecho de que el Estado Español, por medio de sus representantes, interviniera en repetidas oportunidades a favor de los productores. Hay que recordar, además, que muchas plantaciones, por los menos en el caso del valle de Aragua, no eran siempre de los grandes hacendados (los "mantuanos") sino de pequeños cultivadores que se quejaron en repetidas oportunidades del costo del arriendo de las tierras y de la dificultad en conseguir mano de obra libre.

En el marco de las medidas encaminadas a fomentar la producción, Intendencia no sólo autorizó la exportación de añil a las colonias extranjeras a cambio de esclavos y de numerario, sino que procedió a comprar las cosechas correspondientes al año 1786, invirtiendo en ellas los sobrantes de la venta del tabaco, en el momento preciso en que los precios habían llegado al mínimo (9 reales, o sea, 2 reales menos que el año anterior). Estas compras nunca llegaron a suspenderse por completo. En diciembre de 1786, se remitieron a España 17.000 libras de ese fruto; en 1787, 8.163 libras llegaron a Cádiz, con un costo de 14.326 pesos. En 1788, a pesar de haberse

15 MCKINLEY [9], pp. 56, 155 (menciona una carta de Saavedra a Gálvez en este sentido, del 28 de junio de 1784). Gaceta de Caracas, Caracas, Academia Nacional de la historia, 1960, edición facsimilar, 1809-1810. ARCILA FARIAS [1], tomo I, pp. 335-337. 
recibido una orden de suspensión de las compras, se enviaron 137 093 libras y a principios de siguiente año, otras 13.712 libras. Una Real Orden de 28 de febrero de 1787 y otra de 26 de noviembre del mismo año dispuso que se emplearan 125.000 pesos fuertes de la renta del tabaco para "darles valor (a las fanegas de cacao y añil: ésta última costaba entonces 10 reales) y evitar la ruina de los labradores". En 1788, el Cabildo de Caracas solicitó del Intendente que se comprara el añil - pero también el cacao y el algodón- a los cosecheros y que se tratara de invertir de nuevo los caudales líquidos del tabaco en frutos de la provincia. De esta manera, los mienbros del Cabildo querían evitar una disminución drástica de los precios, originada ya en parte por la falta de salidas, tanto para Veracruz como para España.

\footnotetext{
"quedando los vecinos cosecheros sujetos a sólo un comprador que brindan y facultan usarse en iguales críticas circunstancias en todas las ciudades, de cuya falta de salida resulta por ilación presiva la decadencia en sus precios con perjuicio del Estado...".
}

El mismo Arbide llegó a firmar representaciones redactadas por los productores, en las cuales se denunciaba en el monopolio de los comerciantes - a pesar de que hubiese decretado la libertad de comercio - y el papel desempeñado en ese aspecto por varias casas de comercio de la Península (especialmente de Cádiz), y se pedían concesiones similares a la que se habían otorgado a favor de esas empresas. Junto al dominio de unos cuantos comerciantes como los hermanos Iriarte y José Escorihuela, se perfilaba además otro riesgo de monopolio, el del nuevo establecimiento mercantil que sustituyó en cierta forma a la Compañía Guipuzcoana, la Compañía de Filipinas ${ }^{16}$.

La situación mejoró sin embargo a los pocos meses y en 1792 la libra de añil se cotizaba en 13 reales. Este intervencionismo se manifestó a todas luces en otra oportunidad: la Real Orden del 12 de septiembre de 1792 autorizó a los buques provenientes de Veracruz a que hicieran escala en los puertos venezolanos y a que allí embarcaran productos locales, entre ellos el añil, que seguía exento de

\footnotetext{
16 ACM, Actas del Cabildo, 1788: representación del síndico procurador al Ayuntamiento, 18 de febrero de 1788; A.G.I., Caracas, 104: mencionado en el informe del gobernador Guevara Vasconcelos, del 10 de Marzo de 1804 . ArCILA FARIAS [1], t. II, p. 42.
} 
impuestos a su llegada a España. Las guerras entre España y Francia (1793) y contra Inglaterra (1796) dificultaron las relaciones comerciales y ofrecieron a los comerciantes caraqueños la oportunidad de imponer a los cosecheros unos precios mínimos. En 1793, la libra de añil valía 13 reales, pero en 1796, su precio era solamente de 10 reales, o menos incluso si recordamos las disposiciones tomadas en 1793 para garantizar estos precios por parte del Intendente Fernández de León (contra 14 reales antes de la guerra), lo que motivó otra intervención de la Intendencia para que volviera a subir el nivel de los precios (política de compra).

La crisis de finales de 1797 tuvo como consecuencia una disminución conjunta de los precios y del volumen de las exportaciones, situación que se acentuó entre 1800 (la libra se cotiza en 9 reales) y en 1828, año en que la libra de añil alcanza solamente 8 reales. De 2.955.973 libras para el periodo 1793-1796, las exportaciones bajan a tan sólo 793.210 libras entre 1797 y 1800 , con un promedio de precio estimado para el conjunto del periodo de 13 reales la fanega. La progresión de las exportaciones de algodón y de café no logró compensar el deterioro de los volúmenes e ingresos de añil y del cacao. Entre 1797 y 1800, 151.749 libras de añil se exportaron a España y 641.461 a naciones y colonias extranjeras ${ }^{17}$.

Fueron los pequeños productores quienes salieron más afectados: se considera que dos terceras partes de los productores dejaron de explotar sus plantaciones durante la crisis que abarcó los años 17971801. Otras circunstancias contribuyeron en desestabilizar la producción añilera:la sequía de 1804 que encareció los frutos de todo tipo, añil incluido; y los robos, hurtos (incluso de semillas) en las haciendas por los peones o esclavos libres quienes los vendían luego ilegalmente. Fue así como el Teniente de Justicia mayor de Maracay llegó a decretar la prohibición del comercio clandestino por el bando de 1 de octubre de $1794^{18}$.

17 ACM, Agricultura: "Informe sobre la providencia para sostener el precio de los frutos que a instancia del Ayuntamiento tomó el Intendente Fernández de León" (julio de 1793); ACM, Actas del Cabildo: Junta extraordinaria del 10 de abril de 1793; Humberto TANDron, El Real Consulado de Caracas y el Comercio exterior de Venezuela, Caracas, UCV, 1976, p.160. ARCILA FARIAS [1], t. II, pp. 75-77.

18 A.G.I., Caracas, 501: memorial de los productores de añil, 2 de julio de 1878. TANDRON [17], p. 125 AGN, Actas del Consulado, 2529: Juta Extraordinaria del 1 de octubre de 1804 .

R. I., $1998, \mathrm{n}^{\circ} 214$ 


\section{CONCLUSIONES: LAS DESVENTURAS DEL PROYECTO AÑILERO.}

A fines del siglo XVIII, el añil figuraba entre los principales productos de exportación en Venezuela con un promedio anual de 544.608 libras, aprovechando indudablemente la gran demanda que había en ese momento en la península y que logró suplir en casi la mitad. Hay que resaltar, sin embargo, que el añil venezolano, si bien logró rivalizar en la práctica con el primer productor del momento (Guatemala), se benefició de la actitud voluntarista y proteccionista de la alta administración local, apoyada puntualmente por la Corona. Ahora bien, la decadencia del cultivo fue tan sorpresiva como su éxito inicial. Pero no fue sino a partir de 1828 cuando se inició el verdadero declive de la producción y del comercio, ante la competencia originada por otras áreas productivas. En 1805, el Consulado de Comercio de Caracas, en una sesión de 27 de noviembre, puntualizó lo siguiente respecto al aumento del consumo de varios productos —entre ellos el añil - y el consiguiente afán de las naciones a "connaturalizarlos en sus Colonias". Así sucedió con el algodón, el azúcar y luego con el café, y el codiciado añil:

\footnotetext{
“... pues hoy se coge en abundancia tanto en las Indias Orientales, como en las Occidentales: que en aquellas sale mucho más barato por serlo los jornales, a causa de su inmensa población de que tanto se carece en éstas, y aunque antes era de inferior calidad, se advierte por los papeles públicos que el superior está ya en el mismo rango en las plazas de Europa que el nuestro y el de Guatemala, porque tal ha sido el esmero y eficacia de los ingleses en la siembra y beneficio de este fruto en sus extensas posesiones del Indostán, de que ya se surten la mayor parte de las fábricas, y aspira aquella nación enemiga natural y eterna de la prosperidad de todas las demás, nada menos que apropiarse exclusivamente el beneficio y provisión de este precioso y necesario artículo"19.
}

La falta de mano de obra denunciada por los productores - junto al afán de lucro y a los monopolios de los comerciantes españoles, "opresión" de la que fue advertida la Corona en 1787- plantea no pocas preguntas. Quizás el estatuto de los productores (pequeños cultivadores en su mayoría) pueda explicar en parte este fenómeno.

19 Arcila Farias [4], pp. 21-22. 
Por otra parte, la mano de obra esclava disponible estaba trabajando en las grandes haciendas, y - por más que no quiera una atención constante - en las haciendas productoras de otro fruto esencial para la economía local: el cacao. Si bien existían haciendas donde se dedicaban de manera exclusiva a esta producción, el añil ocupaba a veces un lugar secundario en la producción de estas grandes propiedades. De una muestra de doce haciendas que producían añil, en cuatro de ellas se cultivaba como producto secundario, y sólo una se asentaba en tierras arrendadas. El arriendo de las tierras ascendía a diez pesos o más por cada fanega producida en el año, sin contar el jornal de los trabajadores y el costo de la maquinaria. De ahí unas posibilidades de ganacias muy desiguales según que el productor fuera dueño o no de sus tierras (y de la mano de obra esclava) y de un nivel de precio no muy alto ya que escasamente pasaron de 10 a 12 reales por libra ${ }^{20}$.

La desafección por el cultivo añilero sin embargo no se funda en circunstancias locales o en el empobrecimiento de los suelos, consecuencia del cultivo a mediano plazo, y del consiguiente descenso de los rendimientos. También se tiene que relacionar con el desarrollo de la industria química y, sobre todo, con el invento en 1841 por el alemán Fritzoche del colorante que se iba a conocer más adelante con el nombre de anilina, así como con la difusión del prusiato de hierro. En la actualidad, las dos especies de añil que señalamos en la introducción a este trabajo siguen creciendo en forma silvestre en las tierras calientes y sus hojas no tienen otra utilidad que la de curar la sarna ${ }^{21}$.

This articles intends to offer a synthetical view of a not much studied topic within the late colonial economic studies, from a double viewpoint: economical (growth conditions, crop profitability, export and market shares, etc.) and social (performance of the indigo haciendas and patterns of ownership). The shattering course of development of the indigoferea tintorea is followed, from its early import in the Capitania General by Antonio de Arbide to de decline of its incipient market tendencies on the eve of the Independence.

20 AGN, Actas del Consulado, 2528: Junta Ordinaria de 28 de junio de 1802. MCKINLEY [9], p. 78.

21 MCKINLEY [9], p. 149; Rafael CARTAY, Historia económica de Venezuela, 18301900, Valencia (Venezuela), Vadell Hermanos Editores, 1988, pp. 51 y 54. Diccionarios de Historia de Venezuela [1]. 